\title{
Phenomenology is not phenomenalism. Is there such a thing as phenomenology of sport?
}

\author{
Jan Halák ${ }^{1, *}$, Ivo Jirásek ${ }^{1}$, and Mark Stephen Nesti ${ }^{2}$ \\ ${ }^{I}$ Faculty of Physical Culture, Palacký University, Olomouc, Czech Republic; and ${ }^{2}$ Faculty of Science, Liverpool John \\ Moores University, Liverpool, United Kingdom
}

Copyright: (C) 2014 J. Halák et al. This is an open access article licensed under the Creative Commons Attribution License (http:// creativecommons.org/licenses/by/4.0/).

\begin{abstract}
Background: The application of the philosophical mode of investigation called "phenomenology" in the context of sport. Objective: The goal is to show how and why the phenomenological method is very often misused in the sportrelated research. Methods: Interpretation of the key texts, explanation of their meaning. Results: The confrontation of concrete sport-related texts with the original meaning of the key phenomenological notions shows mainly three types of misuse - the confusion of phenomenology with immediacy, with an epistemologically subjectivist stance (phenomenalism), and with empirical research oriented towards objects in the world. Conclusions: Many of the discussed authors try to take over the epistemological validity of phenomenology for their research, which itself is not phenomenological, and it seems that this is because they lack such a methodological foundation. The authors believe that an authentically phenomenological analysis of sport is possible, but it must respect the fundamental distinctions that differentiate phenomenology from other styles of thinking.
\end{abstract}

Keywords: philosophy of sport, phenomenology, phenomenalism

\section{Introduction}

In the Euro-American cultural space, the term "phenomenology" refers undoubtedly to a well-known philosophical discipline founded by Edmund Husserl in the beginning the $20^{\text {th }}$ century. This method of thinking was defined by its unique historical development that gave birth to a particular set of systematic questions, and was progressively developed by a series of foundational authors, their pupils, successors and commentators. Simply put, from the perspective of the presentday researcher, there is a tradition of phenomenology.

In the domain of sport research, however, the meaning of the discipline practiced as "phenomenology" frequently seems to lose any connection with this historically formed unit, or with this tradition, even though the authors expressly refer their texts to it. They allow themselves a great deal of freedom in applying phenomenology-related concepts (such as phenomenon, epoche, essence or structure, subjectivity, lived experience, world) and it seems almost as if their

\footnotetext{
* Address for correspondence: Jan Halák, Department of Recreology, Faculty of Physical Culture, Palacký University, tř. Míru 115, 77111 Olomouc, Czech Republic. E-mail: jan.halak@upol.cz
}

meaning could be modified depending on the authors' actual goal. This situation is, of course, unsatisfactory and ultimately unacceptable. The purpose of this paper is thus to clarify the reasons for which, in our opinion, there is a frequent substantial loss of the meaning - and the value - of phenomenology as it is misinterpreted in sport related research.

We would like to sketch a brief critical overview of a number of representatively chosen, mostly sportresearch related texts which have the ambition to call themselves "phenomenological". We shall demonstrate how the misunderstanding of some of the key distinctions introduced by phenomenological philosophy often brings the authors to even epistemologically inconsistent assertions. These may be interesting from some points of view, but can in no way obtain objective scientific validity in the way the authors wish, i.e. simply by being labeled phenomenology.

As the phenomenology is a discipline stemming from a particular historical context, its fundamental meaning is clearly defined in contrast to certain epistemological and ontological positions. Phenomenology fights especially against two ultimately inconsequent ways of thinking - first, skepticism and psychologism; and second, naive objective realism. The key problem with the majority of sport-research appropriations of 
phenomenology consists precisely in that there is a mismatch being made concerning the exact meaning of the distinctions introduced by phenomenology. Thus without any doubt, the authors introduce all the major phenomenological terms, but they do not securely grasp and clearly explain in contrast to what these have to be understood. Seemingly the same concepts are used, but they acquire an entirely different meaning, as they stand in opposition to something else than they did originally. In other words, if the authors are unable to keep their thinking within the limits that define phenomenology in contrast to other intellectual stances, we can only say that there may be an interesting discipline struggling for approval, but it is not phenomenology. Moreover, if this is the case, it cannot misappropriate phenomenological epistemological and ontological achievements, such as its status of a theory and its generally valid epistemological value.

Our argumentation has three steps: first, we explain that phenomenology is not a preference for the immediate; second, we explain why phenomenology is not a predilection for personal perspective (an empirical subjectivism); third, we explain that phenomenology does not fundamentally deal with objects, that it is not a collection of empirical facts (qualitative research).

\section{Phenomenology is not immediacy}

Let us begin with a brief explanation of how phenomenology understands itself in contrast to other ways of theoretical thinking. The best way to do this will be to explain the meaning of the two Greek words "phenomenology" consists of phainomenon and logos.

The phainomenon of phenomenology is not any appearance - it is the uncovering of "the thing itself". There is a phenomenological phenomenon when the reality starts to "speak for itself", when the thing shows itself as what it is. This is the meaning of Edmund Husserl's fundamental phenomenological slogan "to the things themselves!" (Husserl, 2001, p. 168). Not all "phenomena", however interesting they may be, are thus phenomenological phenomena - a personal impression or even a sensory illusion indeed is a revelation of "something", i.e. it has a meaning, but it is not the phenomenon phenomenology speaks about, quite simply because it does not reveal "the thing itself". Thus, if we observe "ice can look like glass" and assert that we are practicing phenomenology (Nilges, 2004), we are profoundly mistaken. The same goes for all cognitive "preconceptions", "idealizations", theoretical "schematizations" and other "idols" (Merleau-Ponty, 1996) that obstruct our view of how things truly and concretely are. Moreover, as Heidegger explains in the initial paragraphs of Being and time (Heidegger, 2008a, especially § 7), all "mere phenomena" disconnected from the thing itself suppose the disclosure of something real, a real disclosure, a phenomenon in the full sense of the word. In other words, according to phenomenology, all subjective, perspectively deformed "phenomena", delusions or abstractions of any type, presuppose the phenomenon of phenomenology, not the other way around.

There is thus a very high epistemological ambition in phenomenology, which fights first of all the skeptical position inspired by Kantianism, for which "phenomena" are not epistemologically valid, as they have no observable relationship with reality ("noumena"; cf. Kant, Critique of pure reason, trans. 1929, A40/B49). However, the sport-related research discussed in this paper seems to be completely unaware of these epistemological discussions; most of the time, the authors hold pre-phenomenological or even pre-Kantian epistemological stances, as we shall see.

The word logos in "phenomenology" implies, of course, that the discipline possesses necessarily the character of a discourse. In other words, being an interest in "the things themselves", phenomenology is impossible without words and concepts. It is not a practice of sensation, perception or intuition; it is not a simple coincidence with the stream of consciousness, whether its objects would be "external" (perception) or "internal" (introspection). Phenomenology has thus twofold direction and dynamics: retrospective and reflexive on the one hand (back to the things themselves, phainomenon), and prospective and constructive on the other (say what has not yet been said, logos).

The conjunction of the two tendencies is paradoxical only on the first and superficial sight. The paradox of an "immediate account" of experience has been criticized by phenomenologist Merleau-Ponty notably regarding the philosophy of Henri Bergson (MerleauPonty, 1968, chapter "Interrogation and Intuition", in particular pp. 122-125). This author, claiming the necessity of blending with the durée through an immediate intuition (cf. Bergson, 1919, 1992), was a Nobel Prize holder in literature who astounded his audience with exceptional rhetorical skills. Indeed, to be able to make our intelligence blend with the immediate as brilliantly as Henri Bergson did, we need to master at least the principal medium of human communication, the language. Thus, in order to be able to proclaim itself a philosophy, phenomenology requires a specific conceptual work and effort. However it may seem paradoxical in relation to the appeal to get back to "the things themselves", phenomenology is a creative intellectual discipline, the effort of clarification of meaning, and thus necessarily an activity of expression and an active conceptual construction - an ingenious use of language (logos) (cf. Heidegger, 2008a, pp. 28-30). 
How should we understand, then, such a statement as that "perhaps a phenomenological analysis of sport should turn directly to the immediacy of our experience in sport" (McLaughlin \& Torres, 2012, p. 88)? Phenomenology does not deal with what is self-evident and obvious, even if it were from a somehow advantageous standpoint (e.g. the sport-person's). Heidegger (2008a, p. 31) thinks about our problem precisely in this way: "What is it that by its very essence becomes the necessary theme when we indicate something explicitly? Manifestly it is something that does not show itself initially and for the most part, something that is concealed, in contrast to what initially and for the most part does show itself." A mere spontaneous verbal recollecting of "phenomena" in the sense the word has in common English, i.e. as observed existing facts or situations, a letting go to the naive realism of a particular person, does not itself make us phenomenologists. The uncovering of the thing itself does not happen by means of preferring "immediacy", nor does it happen "spontaneously", nor is it an "immersion" in the lived experience, a mere "self-disclosure". "No holds barred" description, an ungrounded attempt to return to some mysterious coincidence with the real, does not guarantee, in any way, the phenomenological quality of the result.

Philosophically, the unspoken meaning of an immediate (sport) experience cannot be reached by holding one's tongue and stopping to think - or just telling whatever is on our mind, which has the same effect. For it can only be restored by thinking and saying better than what is being said by all the constructs and schematizations with only a weak connection to "the thing itself". Yet how do we guarantee this "better" quality, thanks to which we pass from a personal impression to an investigation having general theoretical validity? If we ask the sportsman himself to speak, the meaning of his words won't be "phenomenological" just because of his allegedly closer relationship to the matter itself. If his exposition really is phenomenological, it is because he is himself able to make the experience itself speak, rather than letting speak the explanations that are familiar to us, including the sportsman himself. In such a case, however, he is himself a philosopher mastering the expressive possibilities of the language, so his phenomenological quality does not itself stem from the fact that he is equally a sportsman. In all other cases, it still belongs to philosophers to look upon the (sport) activity of other people and to attempt to make it speak about itself - in short, to practice phenomenology.

So how do we acquire a "direct account of an experience" (Nesti, 2012, p. 105) according to phenomenology? Epistemological immediacy requires effort, not a bigger degree of spontaneity or automatism.
Phenomenology is the dissatisfaction with the selfevident, with our spontaneous and effortless preconceptions. This is exactly the reason why Husserl speaks of the necessity of a phenomenological reduction: in a broader sense, the reduction is the transfer of the "still mute experience [...] to the pure expression of its proper meaning" (Husserl, 1988, p. 38, trans. modified; frequently cited by Merleau-Ponty, e.g. 1958, pp. 254-255). The phenomenological analysis of experience is thus an active operation supposing an effort to get back closer to the nucleus of meaning of the thing itself, howsoever this nucleus is understood (for example as eidos or essence by Husserl, as Being of the beings by Heidegger, as structure by MerleauPonty, as world for Patočka). In phenomenology, one strives to pass precisely from the singular, self-evident view to a more generally valid meaning, independent of our particular situation. Phenomenology is a struggle to overcome the original human situation, in which the explanations are more familiar than what is being explained, when we are losing connection between the meaning of the things for us and the meaning of the things themselves. Phenomenology is the "re-duction" or transfer of the intellectual attention from this singular, peculiar experience and the edifice of constructa it embraces towards the ground from which they rose and from which they still draw their ultimate meaning and intelligibility. (For a positive description of the phenomenological reduction in sport-literature, cf. e.g. Kerry \& Armour, 2000).

In short, as the criterion of immediacy can hardly be held for a sufficient condition of theoretical faithfulness to reality, there is nothing inherently phenomenological about the sole decision to give an "immediate account" of experience. The idea of such an "immediate account" gets easily paradoxical if we understand it too simply, for no account is immediate. Inversely, phenomenology is nothing else than an interminable struggle to pass from this idea to its realization. As Merleau-Ponty put it: "The most important lesson which the reduction teaches us is the impossibility of a complete reduction" (Merleau-Ponty, 1958, p. XV). The subsequent development of phenomenology and its actual state confirms this statement, even if Husserl himself might not entirely accept it. In any case, and in accordance with the texts of all the phenomenologists discussed here, Husserl included, we have to assert that without an active and continuous effort of a purposeful clarification of meaning, we have no right to claim for ourselves the dimension of phenomenological logos. In other words, without such a constantly renewed conceptual work, there is nothing that could defend us from giving up to a mere epistemologically ungrounded phenomenalism - be it subjectively 
skeptic (pseudo-Kantian relativism) or naively objectivist (western science included).

\section{Phenomenology is not subjectivism}

From our explanation to this point, it can be seen already how important it is to discuss the difference between phenomenology and "first-hand experience" (e.g. McLaughlin \& Torres, 2012, p. 88), experience "in the first person", "the subjective view of experience”, etc. Assuredly, Husserl's phenomenology deals with subjectivity and its "mental processes" (Erlebnisse, cf. Husserl, 1982). But what does this mean exactly? "Subjective" experience as opposed to what? It is unquestionably not experience as opposed to the experience of other people, or experience of realities as they objectively are, as some sport-research related authors discussed below assert vehemently.

Husserl strives for a general (a priori) theory of knowledge, so for him, there is no interest in any of all the empirical relationships we can find in the world. For, at least in his opinion, the factual development of the content of our empirical, personal and singular consciousness cannot change the way in which the content or the object is "constituted" within the "transcendental consciousness". All subjective facts are still facts, empirical and particular, and are thus "set aside", "bracketed", insofar as they would pretend to represent any kind of phenomenological knowledge about how the reality shows itself to us. This epistemological position is what makes Husserlian phenomenology a transcendental philosophy, as opposed to empirical psychology or any introspective study of actual and particular stream of consciousness, or even more in general, as opposed to any empirical research (we shall return to this point later). The transcendental subjectivity Husserl speaks about is thus never a mere personal subjectiveness, but rather the very essence of what it means to "be a subject", i.e. to experience something, to have a relationship with reality. The "transcendental ego" Husserl describes is not a concrete person, and the experience described on the level of the transcendental ego is not the experience of a particular person.

Therefore, the "transcendental" structures are not "subjective" in the sense that they would represent a personal perspective, but quite on the contrary, they are entirely objective in the sense that they are necessary for any empirically subjective experience of real objects to take place. In short, they are the a priori conditions under which any type of object can only show itself as what it is. This is also the reason, why the interest in "phenomena", which are "immanent" to the consciousness, is equivalent for Husserl to the interest in "the things themselves" which are obviously transcendent. The description of this "correlation", as Husserl calls it (e.g. 1970, § 46), between the independent reality and the way in which it is experienced by someone, is the principal task of phenomenology.

In this way, Husserl deals with the factual or even empirical events (objective as well as subjective) only to the extent that he can extricate from them an eidetic (essential) transcendental knowledge. In other words, he is not looking for facts, he is not primarily interested in describing some particular contents filling up our world (be it feelings or impressions of a particular subject), he is not collecting "empirical data", verifying hypotheses, doing experiments, asking specific people specific questions. For according to Husserl, a mere collection of facts does not make us understand how there is, and ever can be, a fact for us (cf. Husserl, 1966, Lecture I.).

We believe that all the other important authors traditionally included in the phenomenological movement further pursued this "transcendental" orientation of phenomenological philosophy, even if the term itself, linked to the Kantian conception of human experience as intellectual process taking place in the consciousness, was not used anymore. Thus, later on, phenomenology ceased to be the study of the transcendental structures of the consciousness, as it was for Husserl, and became ontology (e.g. Heidegger, 2008a; Merleau-Ponty, 1968), an "asubjective" description of the "world" for others (e.g. Patočka, 1998; cf. Bednáŕ, 2006; Martínková, 2006; Učník, 2007), or even a cosmology (e.g. Fink, 1960). However, in the sport research domain, the transcendental orientation of phenomenology, i.e. the fact it is an investigation of the conditions of experience, seems very often to be completely ignored. Let us thus shortly explain how some authors representative of the way phenomenology is misinterpreted in sport related research fail to understand that Husserl's "transcendental subjectivism" is not an epistemologically subjectivist position.

The goal of one of the texts by Gregory A. Dale, for example, is to promote "the subjective experience of the athlete as a viable resource of information" (Dale, 1996, p. 307), as opposed to the description of the event from the outside, with no personal participation in the activity. This "first-person description of experience" (p. 309) focusing on "the participant's experiences" (p. 310), i.e. a description of the "human life as it is lived and reflected upon in its first-person concreteness" (p. 309), is to be obtained by means of so-called "phenomenological interview" (p. 307). The purpose of this dialog between the researcher and the participant, who is considered to be an "expert on the phenomenon" (p. 313), is to "clarify the meaning" of the experience (p. 310) in order to obtain "qualitative data" (p. 315). 
It should be already evident in light of our introductory explications that the intellectual position described here does not coincide with phenomenology. Our brief summary demonstrates clearly enough that Dale's (1996) idea of "phenomenological" research involves an empirical inspection of facts, where "phenomenon" has no particular phenomenological signification and refers only to empirically understood "qualitative" (i.e. meaningful) data or information; where subjective experience is understood as empirically subjective, i.e. as the experience of a concrete person; finally where to "clarify the meaning" means to say what it means to me, as a concrete, empirical person involved in the activity (cf. p. 310). (Exactly the same distortion: Nilges (2004, p. 299) and other authors discussed below; compare Hughson \& Inglis (2012): "existential-phenomenological reconstruction of play as experienced by a soccer player" (p. 2), a "definition of play, especially in terms of how it "feels"' (ibid.); McLaughlin \& Torres (2011), rely on citations from McGinn (2008): "knowledge of what it feels like" (p. 68, italics added), description "from the inside" (p. 13, italics added); Kretchmar (2000), relies on an analytical description while investigating the meaning.)

Such research cannot be criticized in itself and may have a kind of validity of its own. However, the notion of phenomenology is simply misused here in order to explain the difference in approach between two empirical methods that the author is unable to explain in a different way. Within such a phenomenalist (at the most) framework, the principal characteristic that makes this text unacceptable from the methodological point of view is precisely its explicit reference to historically established phenomenology: we read about the "phenomenological reduction" as the "consciousness of one's presuppositions" (Dale, 1996, p. 311), about the "life-world" (p. 318) as the actual experience of a concrete person, about "bracketing" as a way of removing personal bias (p. 315), about "hermeneutic circle" (p. 315), etc. All these notions are adopted from Husserl's and/or Heidegger's philosophy, and they are fundamentally distorted in their meaning basically because the author mixes up the transcendental and the empirical approach to experience, the investigation of eidetic structure with the search for factual occurrences (e.g. the opinion of a particular player). There is nothing inherently phenomenological in the sole use of personal experience, as even the most objective and/or positive sciences such as mathematics and physics would not exist without scientists qua persons and their personal experience; or as any person suffering from hallucinations also have "personal experience", in this case without any epistemological validity, i.e. the right to claim them to be experience of truth. The author uses phenomenology as a shield against the research based on quantification, because he is unable to formulate the difference of his approach in a positive manner. The fundamental fact is ignored that phenomenology does not fundamentally deal with a particular stream of a concrete experience of a particular person (phenomenalism), but with the essential structures of experience in general (phenomenology).

Here as well as in other texts with similar flaws, the fundamental problem seems to be that the author does not even work with the original textual sources and feels sufficiently confident with his mistaken idea simply because there is a substantial body of literature already prone to this misleading use of the terms (cf. the list of Dale's references, 1996, pp. 309-310). The meaning of the original phenomenological method remains practically undiscovered, the author builds his ideas on summaries of summaries of the original texts and imposes unacceptable generalizations, especially concerning Heidegger, whose fundamental ontology is labeled "a holistic psychology" or a "combination" of Husserl and Kierkegaard (p. 309). Unfortunately, almost the same type of misuse of phenomenological notions, flattened and emptied of its concrete contents, is presented in many other texts dealing with sport related topics.

Walker (2007), for example, defines phenomenology correctly as a research approach striving to gain "insight into the essence or structure of the lived experience" (p. 36). Yet surprisingly, for her this means finally to produce a description "from the perspectives of those being studied" (p. 36), to recall "the participants' perceptions of events" (p. 37) with the goal to "preserve the uniqueness of each participant's lived experience" (p. 43). The author builds on a considerable amount of theoretical sources (e.g. Knaack, 1984; Polit \& Hungler, 1999; Rose, Beeby, \& Parker, 1995), but in the course of the concrete interpretation and application of the thought of phenomenology, she quietly drops out the notion of "essence" or "structure". In a similar manner, other authors presume that the essence means simply "what was it like" (Nilges, 2004, p. 300), "what it feels like" (McGinn, 2008, p. 68) for the particular person involved. This implies an unacceptable reduction of phenomenology to a merely "personal" experience, to a "self-disclosure" or to an "immersion in the lived experience of others" (Walker, 2007, p. 40) as opposed to the experience intersubjectively shared and demonstrated as truthful for everyone, as well as to essential structures phenomenology speaks about, which are valid in a general, transpersonal and trans-temporal manner. Neither Walker nor the other authors demonstrate, in any way, how from one's own personal experience we pass to the 
aforementioned essence or structure of experience: the transition from "subjective" experience to the essence of experience is left entirely ungrounded. Simply put, we do not know how the authors want to guarantee that we do not deal with only a particular, inessential, incidental assortment of experiences. Yet this is, in our opinion, both a serious methodological flaw and the main reason for which phenomenology is reduced here to a plain subjectivism or phenomenalism dealing with merely subjective experiences, as opposed to the conditions related to the subject which are necessary for the experience in general (transcendental subjectivity).

All the phenomenological notions subsequently employed by the authors thus acquire a totally different meaning than they had for Husserl and other phenomenologists, and serve henceforth as instances of its subjectivist misinterpretation: "life-world" (Walker, 2007, p. 40), "phenomenon" (p. 42), the experience "as lived” (p. 37), "bracketing” (p. 42), "epoche” (Stoll, 1982, p. 13), understanding (Stewart, 2006). As we can see in Nilges' (2004) case, this can lead to a rather tragicomic confusion, when the general orientation of the consciousness towards objects ("intentionality") becomes simply dependence of the meaning on one's personal intention: intentionality as a "personal meaning” (p. 312), "highly individualized" view (p. 299), etc.

These basic misunderstandings of the idea of phenomenology, let us say it again, show a complete lack of knowledge of the original texts, in particular those by Husserl, who explicitly addresses precisely the same topics and fundamental distinctions, especially between the transcendental and the empirical subject. The authors just confuse what lies at the very foundation of the idea of phenomenology, the difference between the essential structure of experience, or the transcendental characteristics of the subjectivity, and a concrete, particular subject with his/her "opinion" or "feeling". The inability to respect this differentiation makes these authors' claims epistemologically implausible, or at least methodologically ungrounded, as far as they expect such a foundation from phenomenology. The transition from the empirically subjective experience to the transcendentally subjective structure is methodologically very well grounded in Husserl's phenomenology by the "phenomenological reduction" (sometimes further differentiated in transcendental and eidetic reduction). For example the "pure" phenomenon of time is, for Husserl, the inextricable linkage between the "still here" character of the recent past, the intensity of present perception, and the pressure of imminent events - it is neither the objectively measured time of a runner (how many seconds?) nor the runners' inner feeling (does time "run fast", am I bored?). (Cf. Husserl, 1964, as opposed e.g. to Aristotle on time, Physics, trans. 2008; Metaphysics, trans. 2004; for a sound phenomenological discussion of the topic of time in sport literature, see Bednár., 2003; Hogenová, 2006; Jirásek, 2007; or Martínková, 2007.) As the phenomenon is not a "feeling", it does not occur simply "by itself", and it requires a very specific intellectual attitude and effort, thanks to which we get through a process of imaginary and descriptive variation in order to uncover an invariant and pass from the factual experience here and now to the eidos, or the essence, of this experience. We ask, for example, which structural features have to be present in order to permit the existence of a "time object", and we find that any time object has to hold together and link in an orderly manner the phases of "not any more", "right now" and "not yet". We intellectually and descriptively search for the limits beyond which the phenomenon described loses its meaning and ceases to be what it is for us. We are not discussing the relationships between particular objects in time, for example, because such discussions precisely presuppose the phases of the time object already linked together, and are subordinated to the generally valid structure described as the "pure" phenomenon of time.

Thus the experience "as lived" (e.g. Osterhoudt, 1974, p. 139; Walker, 2007, p. 37) does not by itself mean a phenomenologically understood experience. Likewise, Husserl never stresses that what, in the subjective experience he studies, is opposed to the experience of other subjects (as Nilges and others do). He stresses that which, in the subjective or intersubjective experience, is leibhaftig, i.e. given with an original evidence, as opposed to that which does not pertain to the particular phenomenon studied, and is given only as an assumption. This is simultaneously why, finally, all scientific hypotheses are also excluded, why the results of empirical research are understood as irrelevant, and why we talk about the world "as lived". The "facts" coming to us from the world, and thus also all the scientific observations using them as their necessary foundation, need the constituted world and the objects filled with meaning - they only build on the ground of the "constitution" of the experience itself, which is precisely described by phenomenology, and thus cannot bring anything radically new that would change it.

Thus, far from applying a predilection for a merely subjective experience, Husserl is looking for that which is common to all subjectivities in general. We can see that authors criticized in this section of our text simply fail to identify in contrast to what Husserl is using the expressions such as "subjective" or "as lived" - such an experience is understood in phenomenology as opposed to the experience of relationships between 
the constituted objects (relations also studied by all empirical sciences), whereas the sport-research related scholars mentioned above proceed as if it meant the experience as opposed to what others may live, a personal experience.

\section{Phenomenology is not empirical research}

Just as phenomenology is interested in "mental processes", it is also interested in realities transcending human consciousness. The word "phenomenon", says Husserl, is essentially ambiguous, referring both to the subjectivity-related ways of appearing and to the object that appears (e.g. 1966). But again, in what sense does phenomenology deal with realities, with what we can observe as given in the world? Again, it is only to the extent that it can use these facts as the ground for the explication of what it means to be an object, a segment of reality, in order for us to have experience of it. This differentiation can be seen accurately in the examples of the analyzes of the play by Huizinga (1955) and Fink (1960, 1968), who respectively adopt more empirically and meaning-oriented analysis of the phenomenon.

The importance of the phenomenological "epoche" as the abandonment of our preconceptions lies exactly in the resolution not to transfer the "real", empirical and factual, relationships "object-object" to the transcendental relationship "subject-object", for we can only study the relationships between objects in the world thanks to the transcendental relationship, not the other way around. In other words, the experience and the subjectivity cannot themselves be held for objects, for it is only thanks to them that we have objects; and, if this is the case, our factual knowledge about objects has nothing to tell us about the very possibility that we can, in general, have relationships with objects.

This does not mean, however, that facts are simply irrelevant for phenomenology. It is well known, for example, that the method Husserl used to describe the transcendental structures was by following a system of "transcendental clues" (cf. e.g. the title of $\$ 21$ in Husserl, 1988). This means that he described the eidetic transcendental structures on factually or even empirically given objects, and nowhere else. When describing the "pure" phenomenon of time, or the essence of time object, Husserl used the example of a resonating tone. Phenomenological "intuition of essences" would be impossible without a fundamental contact with the "real" (i.e. not merely subjective) world which is the world of given objects: the essence or the meaning is precisely explicated by means of an "eidetic variation" performed on a factually given object, be it an ideal or an empirical one. The importance of the study of facticity is not stressed very much by Husserl himself, especially in his first period, but acquires much more importance in his later thinking (which becomes the study of the Lebenswelt, the world "as lived") and in the subsequent development of phenomenology. It is well known, for example, how Heidegger succeeded in explaining the importance of the mortal character of our existence (facticity) or the fact that we are prone to have different "moods". These facts related to human existence did not seem to be essential for Husserl, but Heidegger was able to show their transcendental value, their fundamental role in the constitution of experience. In a similar manner, for example Merleau-Ponty has shown the fundamental role played in our experience by our body which is the archetype of all human facticity: as a body, we were born and will die one day, we have sexual drives, various acquired habits, undergone pathologies, etc. The three authors we just mentioned, as well as for instance E. Fink or J. Patočka, worked phenomenologically and each of them was able to include different factual observations in their research, and revealed the transcendental structure of human existence in a new, hopefully more complete way.

Thus, it has to be stressed very strongly that even if we are phenomenologically interested in facts or observable realities in the world, which can also include those revealed by science, this does not mean that the purpose of this interest is to collect such facts. The focus of phenomenology remains always on the meaning of the facts. As we can see especially on the example of Merleau-Ponty (1958, 1963), even if we discuss everything which is revealed by physiology or medical pathology, these facts are studied only to the extent to which it can be shown that they have some transcendental value. This is basically what differentiates phenomenology from empirical science, even the "qualitative" type: dealing with the same realities, the approach to them is absolutely different. If the epistemological goal of phenomenology is not to collect facts but describe how there are facts for us, the concrete objects on which these structures are demonstrated do not play any fundamental role and have no special importance (in the same way as it has no importance whose empirically "subjective" mental processes are studied). The transcendental structures are transcendental precisely if the facts cannot overturn them, i.e. if it is only through them that there are any facts for us.

Therefore working with facts in phenomenology brings a big challenge: the purpose of such research cannot be merely to collect the facts (which is always done on the basis of an essential structure, or meaning which is familiar to us already), but instead, the phenomenologist has to show the essential value of the fact studied, for otherwise we would fall outside of the regime of phenomenology. In other words, in phenomenology we are not interested in facts or particular 
cases if we cannot show that they are essential in regard to our experience as such.

Unfortunately, the sport research related "phenomenology" is very often unable to reach such level of philosophical quality. Here, "phenomenon" can only mean a particular reality in the world, with no eidetically transcendental pertinence at all. There is for instance the definition of its particular objective characteristics, its differentiation from other events, entirely objectdirected analysis from the bio-mechanical perspective; there are examples of analyses that discuss the continuum tourism-pilgrimage (Cohen, 1979), styles and elements of snowboarding (Loland, 2007), characteristics of festivity (Eichberg, 2009a), the connection of song and movement (Eichberg, 2009b), some others that look for connections between sport and laughter (Eichberg, 2009c). All these descriptions of "phenomena" are labeled as phenomenology, but the authors do not strive at all for a description from the point of view of the essence of our experience.

The challenge opened by the phenomenological approach to facts opens also the big question whether a mere application of a phenomenologically described essential structure of experience can have the right to call itself a "phenomenology". There are some "correct applications", in which phenomenologically described transcendental structures are applied to a specific sportrelated context (cf. for example Arnold, 1983; Harper, 1969; Hogenová, 2009; Hogeveen, 2012; Hughson \& Inglis, 2002; Kretchmar, 1974; Meier, 1975; Martínková, 2012; Papadimitriou, 2008; Standal \& Moe, 2012; Vannatta, 2008). There is, however, also another type of texts, where the borderline between phenomenological and empirical research remain unclear and where the authors do not seem to understand clearly what the essence of a phenomenological investigation is. It is on these texts that we would like to focus in the following paragraphs.

One of the main and the most frequently cited sources of Dale's (1996) text is Fahlberg, Fahlberg, and Gates (1992); both of them also share their main source - Polkinghorne (1989). In Fahlberg's et al. case, there seems to be a considerable shift in the right direction. Although the authors never mention or distinguish between empirical and transcendental research, they seem to recognize, at least on the theoretical level, that a phenomenological investigation "emphasizes the essential structure of consciousness through which experience is organized and made meaningful" (p. 181). However, even if the authors also stress the importance of the meaning (e.g. p. 184), they again speak of "data collection" and "data analysis" (p. 184), and the principal method for them is, again, an interview with a concrete participant. In this way, it becomes unclear what exactly are the authors looking for: looking for "data", will they automatically find any structurally essential "meaning"? In our opinion, a "datum" is precisely a concrete occurrence of a pregiven meaning, specified beforehand by the research question or the working hypothesis, so the orientation of the research seems inverted if we compare it with the phenomenological method.

This methodological shift, which is, in our opinion, a shift from phenomenology to empirical research, is indeed clearly visible in the authors' conclusion. Although they claim that phenomenology reveals "essential structures" of human experience, their work seems to be only empirical application to a particular case of an essential structure revealed and described not by them, but by Heidegger (2008a). In other words, the authors formulated their research question with the help of a meaning developed by phenomenology, but this question is itself related to an empirical, not phenomenological, research. Their argumentation can be summed up as follows: humans are beings that understand themselves as a whole, i.e. there is a meaning in every particular activity humans do; the same activity (e.g. exercise) can thus have different meaning in different cases (research hypothesis); this applies even to dependencies, therefore even exercise dependency has a meaning (fact observed). Far from applying a phenomenological method (which the authors, in fact, present only very briefly), the only characteristic connecting the text to phenomenology is that it makes use of a particular topic treated by one of the phenomenological authors, Heidegger. Furthermore, the authors merely (re)discover that humans are not exclusively material objects, i.e. that their behavior is properly intelligible only with regard to the meaning it has for them. This simple fact does not seem strong enough to differentiate this "phenomenology" from empirical investigation, in particular from the social sciences in general. So again, the research may not need to be criticized with regard to its concrete contents, but the authors fail to demonstrate what is inherently "phenomenological" about it - their methodological reference to phenomenology does not have any reasonable foundation, as they only apply empirically a particular content borrowed from phenomenology.

In conclusion, the authors seem to have studied the original phenomenological texts and they cite them correctly, but their concrete work cannot, in any case, be taken for phenomenological, as they investigate only a factual applicability (or inapplicability) of a particular type of phenomenologically revealed general structure. The question of factual existence or nonexistence of a "phenomenon" (the presence of a meaning in a particular case of exercise dependency) is in no way 
a phenomenological question, but clearly an empirical one, and the two questions stem from a totally different epistemological attitudes.

With the example of Breivik's work on skydiving (2010), we can show in even more depth how challenging is every attempt to produce a phenomenology of sport activity. Breivik basically tries to uncover an essential trait of human existence on the basis of an analysis of a particular type of human activity, skydiving. Such an attempt to describe a fundamental, transcendentally eidetic value of a particular, concrete activity deserves in itself our appreciation, especially as it is also based on a thorough study of the original source of inspiration, Heidegger's Being and time (2008a). Concretely, the author strives to show that the first act of skydiving opens up the "original situation" of being "thrown in the world" (p. 30); more precisely, when falling through the air, "there is no longer a world" (p. 32), because the "equipmentality breaks down" (p. 32) and so "the being in the world has become a being in the void" (p. 33); this, in turn, would make it possible to confront ourselves actively with the possibility of our death, which means finally that it would make our life "authentic" (as understood principally by Heidegger).

Without getting into the details of Breivik's argumentation, let us show briefly how, here again unfortunately, the author fails to differentiate the factual structure from the transcendentally essential one, and how for this reason he fails to provide a phenomenological account of the sport activity concerned.

First, the "world" is, for Heidegger (2008a), a fundamental structural moment of Dasein: "the worldliness of the world [...] is an existential determination of being-in-the-world, that is, of Da-sein"; "the world [...] was characterized as a structural factor of being-in-theworld", that is, of Dasein (p. 82 and p. 94). So the idea brought out by Breivik (2010), that the original way of living of Dasein and the starting point of authentic existence is "solus ipse, a worldless self", "worldless subject" (p. 40 and p. 48), goes straight against the core of Heidegger's analysis of human existence. How could we imagine Da-sein without the Da? The world as understood by Heidegger, i.e. as an existential (or as Husserl would say - eidetic, transcendental) structural characteristic of Dasein, is not based in perceptible space, but inversely, "physical space" is founded in the world and the worldliness of Dasein. Heidegger's goal is to show, for instance, "how the aroundness of the surrounding world, the specific spationality of the beings encountered in the surrounding world is grounded in the worldliness of the world, and not the other way around, that is, we cannot say that the world in its turn is objectively present in space." (Heidegger, 2008a, p. 94, italics added). Furthermore, Heidegger explains clearly that Dasein is originally Mitsein, being together with others, and not, in any way, an isolated being, solus. Thus, even when being factually unable to perceive the presence of physical space, or when being factually isolated from the others, we do not encounter a "disintegration" or "disappearance" of the world, as Breivik suggests (p. 29 and p. 30). In other words, the "existential”, generally valid structure of our existence, named "world" by Heidegger, is in no way affected by any circumstantial absence! In short, it is not a factual structure which could be present or absent, it is the transcendental structure which is the condition of possibility for every factual absence or presence.

Our conclusion is confirmed more concretely if we penetrate deeper into Breivik's (2010) explanation of the example of skydiving. The author spends a considerable amount of energy to persuade us that when in a free fall, there is no world structure for us the world allegedly "falls apart", "disappears" (p. 29). However, the author did not succeed in explaining why he interprets the absence of some concrete contents of experience as an absence of the world (understood as the transcendental structure of existence). In our opinion, it is evident that this understanding of Heidegger's analysis is mistaken not only formally, but even in terms of simple descriptive fidelity. Breivik's assertion that in the case of the free fall, "the context as such is missing [...] there is no world, but only a void" (p. 34) is grounded on too narrow an understanding of the "context" and thus on a misunderstanding of the concept of world.

Worldliness cannot be reduced to "all the functioning equipmental totalities and contexts" (p. 32; cf. Breivik, 2007). As the skydiver jumps from somewhere (plane) to somewhere (ground), from some altitude to point zero of altitude, the jump and the fall are never a step outside of all context, i.e. the context as a structure of our experience is never completely missing. But the authors' description, which is more expressive than accurate, overlooks this context and leads us into confusion.

This structure from-to, up-down may be lived very intensely as somehow problematic, confused or suspended, but it is never absent, as every skydiver acts on its ground and understands in all circumstances that he/she is precisely falling, down, from above. We may not be sure at the moment where the up and the down is, but we know all the time that there is an up and a down, the ground and the sky, and that we have to act accordingly. The world is not only the prosaic equipmentality of the carpenters' workshop Breivik speaks about, but also the big dimensions such as the resistant ground and the open space of the sky. This is clearly visible on Heidegger's own subsequent development 
and his evidently wider understanding of worldliness of the world not merely as equipmentality (cf. Heidegger, 2008b). The oriented character of the free fall that enables us to perceive it meaningfully as a threat to our life is precisely the structure that Heidegger calls "world". If the world were actually absent, the act of jumping would not be so emotionally challenging. It would not have any meaning at all.

In conclusion, here again, the author's problematic application of the concept of world in the case of skydiving demonstrates clearly that he has not grasped the fundamental difference between a necessarily existing fundamental structure (the worldliness of Dasein) and a factual, empirical, circumstantial occurrence that may, or may not, exist (the absence of the "world" as a part of the complex of objects we can act upon, stand on, etc.). The author fails to understand the difference between a privative modality of the presence of the world (something is missing, for example the ground) and the absence of the world itself (the structural possibility of the presence or absence of a particular segment of reality). This confusion is also clearly visible in Breivik's other assertions, such as that "to establish a world takes time" (2010, p. 34) or that it is a "long learning process" (p. 35). Breivik's "world" is, at best, a factual structure that can be present or absent, that can arise or disappear - it is not a phenomenon as understood by phenomenology, i.e. a transcendentally essential structure of experience. We are thus outside of the regime of phenomenology.

As a matter of fact, Breivik's text (2010) would fulfill almost perfectly the definition of basic-level empirical research, in which a well-known hypothesis is tested and confirmed in a new, particular context. However, the author presents his findings as if they somehow revealed an essential trait of human experience and life - he claims that by involving ourselves in high-risk situations, by "losing control" (p. 40) of our equipmental environment, we become "authentic" in the Heideggerian sense, i.e. we gain access to the truth of our existence. However, as the connection between the authenticity and risk-taking activity is grounded on a faulty interpretation of the concept of world, understood as a factual and therefore destructible structure, Breivik's conclusion should not be accepted. Moreover, by using the expression "being-in-the-void" (with hyphens), the author mimics the Heideggerian way of describing the fundamental structures of existence, whereas he did not unveil any. (The same grief applies to at least one other author who uses an analogically misguided pseudo-Heideggerian expression "being-on-the-bench" - Ryall, 2008.) The only point that has been proven, in our opinion, is that Heidegger's analysis of the worldliness of Dasein is valid even in the particular case of "falling through empty air" (Breivik, 2010, p. 30). In other words, the fundamental structure of human existence described phenomenologically by Heidegger was proven precisely as fundamental, valid in general and independent even of this particular context, because the fact of standing on the ground or falling through the air did not force us to change anything about it. In short, Breivik confuses the factual void ("empty air") with an ontological void ("world is missing"), whereas any factual absence is precisely possible only on the ground of the ontologically relevant presence of Dasein, i.e. of the fundamental structure being-in-the-world.

Finally, in the recent article by McLaughlin and Torres (2012), we can see how problematic it still is to see clearly the boundary between phenomenology and a simple empirical recollection of a (first-person) experience. The authors assert that "the determination of what is rational or meaningful in a given context can in some instances be specific and relevant only to that context. [...] Therefore, doubt can be cast on the applicability of phenomenological insights to sport that are derived from phenomenological analysis unrelated to or disconnected from sport" (McLaughlin \& Torres, 2012, pp. 88-89). This means for us that the authors either do not understand the eidetic character of phenomenology, or they disapprove of it - in both cases, any further reference to phenomenology is prohibited, which is not in harmony with what the authors claim in the rest of their paper. If our insights are not at least presumptively eidetic, i.e. acceptable in general, we are not anymore on the ground of phenomenology - we are at the most on the ground of phenomenalism or naive realism, and the totality of our discussions deal only with "phenomena" in the ordinary sense, i.e. we talk about particular objects in the world as viewed by someone particular and we deal with these "data". Our initial impression is confirmed by the authors' claims about the "subjective" character of phenomenology (ibid., pp. 88-89; the authors use a quotation from McGinn, 2008, and Moran, 2000), understood here again as empirically subjective, not transcendentally. Yet McLaughlin and Torres still present their text as "phenomenological" and, adding to the general confusion, they finally assert that the notions of horizon and intersubjectivity, as developed by phenomenologists and presented by the authors, "are actually constitutive elements of human experience in general" (McLaughlin \& Torres, 2012, p. 89) - therefore eidetic transcendental characteristics, as we would say with Husserl. Thus, even if we consider the authors' conclusions regarding horizon and intersubjectivity as quite authentically phenomenological, the notion of "phenomenology" seems to be very fuzzy for them: there is no clear explanation of the relationship between the mere empirical 
subjectiveness of "phenomena" and their proclaimed objective epistemological value. The authors' philosophical position in regard to phenomenology thus remains unclear and so it does for their reader.

\section{Conclusion}

We have to conclude finally that the inability to discern transcendental subjectivity from personal subjectiveness entails a confusion of phenomenology with psychological subjectivism or phenomenalism, and the inability to discern transcendental structures from factual objective structures entails a confusion of phenomenology with empirical research (be it "qualitative"), i.e. with an epistemologically naive realism (be it that practiced by the western science). Even if some of the authors have the ambition to uncover some "essential structures" of experience, they still describe mostly empirically subjective or objective "phenomena" in the common sense of the word. Yet, as we tried to explain, the phenomena that phenomenology speaks about are not empirically subjective, nor empirically objective, they are the meaning of the thing without which there is no such thing - they represent the core of the meaning of a particular type, they are eidetic, essential or epistemologically fundamental structures of experience.

We very much doubt that the kind of arguable application of the notion of phenomenology we describe here is due simply to a plain interpretative incompetence. The authors link their work to the historically established discipline, naturally because they need an epistemological or even ontological foundation for their actual research - which they feel is, somehow, valid. And phenomenology seems to provide it, i.e. it offers a way in which a personal, singular view of the world can be studied and described with a general validity. (And this has to be a correct standpoint, because we have access to reality even as individuals.) Yet, since the authors did not accept the "phenomenological attitude" and still conserve the "natural attitude" (Husserl, 1982), which does not deal with phenomenological phenomena but with realities, their attempt to take over epistemological validity from phenomenology can never be successful.

However, as we have already noted, the relationship between empirical and transcendental structures, at first understood by Husserl as a strict opposition, became more complex as phenomenology itself developed. For Merleau-Ponty, for example, the relationship between the facticity and transcendentality is that of a circular interdependency (see for example MerleauPonty's discussion with sociology - 1964). This opens, in our opinion, a space for a possible phenomenology of sport, which many authors called for a long time ago (Meier, 1984; Osterhoudt, 1974; Weiss, 1982). For this means that the phenomenology is not an out-worldly "intuition of essences" that would progress with no relation to the factual world, notably the world where humans do, or do not, practice sport. Since we still can get such an impression from some of the perhaps more narrowly Husserlian presentations of phenomenology (e.g. Martínková \& Parry, 2012), we have tried to present a somewhat broader image of phenomenology with respect to its post-Husserlian development, especially to its reflection by Merleau-Ponty. (The importance of this author for sport research has been already stressed, cf. Fielding, 1999; Hughson \& Inglis, 2002; Meier, 1975; Morris, 2003; Waldenfels, 2008.) The fact that humans practice sport can be studied phenomenologically, i.e. it can be explained in regard to its potential relevance for experience and the human condition in general. Unfortunately, as far as we know, such a faithfully phenomenological investigation of sport activity remains to be written, as the majority of acceptable "phenomenological" papers on sport remain primarily correct applications of the essential structures disclosed by some of the classical phenomenologists without any consideration of sport.

\section{Acknowledgment}

The study was supported by the project "Support for creating excellent research teams and intersectoral mobility at Palacký University in Olomouc II" (reg. no: CZ.1.07/2.3.00/30.0041). Jan Halák's work on this article was supported by Jan Hus Foundation.

\section{References}

Arnold, P. J. (1983). Dimensions of being in sport. In H. Lenk (Ed.), Aktuelle Probleme der Sportphilosophie - Topical Problems of Sport Philosophy (pp. 162-168). Schorndorf: Verlag Karl Hofmann.

Bednář, M. (2003). Sportovní prožitek a temporalita lidské existence [Sport experience and the temporality of human existence]. In J. Kirchner \& P. Kavalír̆ (Eds.), Prožitek a tělesnost (pp. 22-28). Praha: Asociace psychologů sportu České republiky.

Bednář, M. (2006). Movements of human existence as a possible background for the study of sporting life. Acta Universitatis Palackianae Olomucensis. Gymnica, 36(2), 11-16.

Bergson, H. (1919). Creative evolution. London: Macmillan.

Bergson, H. (1992). The creative mind. New York, NY: The Citadel Press. 
Breivik, G. (2007). Skillful coping in everyday life and in sport: A critical examination of the views of Heidegger and Dreyfus. Journal of the Philosophy of Sport, 34, 116-134.

Breivik, G. (2008). Bodily movement - the fundamental dimensions. Sport, Ethics and Philosophy, 2, 337-352.

Breivik, G. (2010). Being-in-the-void: A Heideggerian analysis of skydiving. Journal of the Philosophy of Sport, 37, 29-46.

Cohen, E. (1979). A phenomenology of tourist experiences. Sociology, 13, 179-201.

Dale, G. A. (1996). Existential phenomenology: Emphasizing the experience of the athlete in sport psychology research. The Sport Psychologist, 10, 307-321.

Eichberg, H. (2009a). Sport as festivity: Towards a phenomenology of the event. Sport, Ethics and Philosophy, 3, 215-236.

Eichberg, H. (2009b). Song and movement: Phenomenology of human "energy". Sport, Ethics and Philosophy, 3, 237-252.

Eichberg, H. (2009c). Sport and laughter: Phenomenology of the imperfect human being. Sport, Ethics and Philosophy, 3, 286-304.

Fahlberg, L. L., Fahlberg, L. A., \& Gates, W. K. (1992). Exercise and existence: Exercise behavior from an existential-phenomenological perspective. The Sport Psychologist, 6, 172-191.

Fielding, H. (1999). Depth of embodiment: Spatial and temporal bodies in Foucault and Merleau-Ponty. Philosophy Today, 43, 73-85.

Fink, E. (1960). Spiel als Weltsymbol [Play as symbol of the world]. Stuttgart: Kohlhammer.

Fink, E. (1968). The oasis of happiness: Toward an ontology of play. Yale French Studies, 41, 19-30.

Harper, W. A. (1969). Man alone. Quest, 12, 57-60.

Heidegger, M. (2008a). Being and time. New York, NY: Harper \& Row Publishers.

Heidegger, M. (2008b). On the origin of the work of art. In Basic Writings (pp. 143-212). New York, NY: HarperCollins.

Hogenová, A. (2006). Movement and time. Acta Universitatis Palackianae Olomucensis. Gymnica, 36(2), 47-51.

Hogenová, A. (2009). Cartesian bodies and movement phenomenology. Sport, Ethics and Philosophy, 3, 66-74.

Hogeveen, B. (2012). Skilled coping and sport: Promises of phenomenology. In I. Martínková \& J. Parry (Eds.), Phenomenological Approaches to Sport (pp. 61-71). London: Routledge.

Hughson, J., \& Inglis, D. (2002). Inside the beautiful game: Towards a Merleau-Pontian phenomenology of soccer play. Journal of the Philosophy of Sport, 29, 1-15.

Huizinga, J. (1955). Homo ludens: A study of the play-element in culture. Boston, MA: Beacon Press.

Husserl, E. (1964). The phenomenology of internal time-consciousness. Bloomington, IN: Indiana University Press.

Husserl, E. (1966). The idea of phenomenology. The Hague: Martinus Nijhoff.

Husserl, E. (1970). The crisis of European sciences and transcendental phenomenology: An introduction to phenomenological philosophy. Evanston, IL: Northwestern University Press.
Husserl, E. (1982). Ideas on a pure phenomenology and on a phenomenological philosophy. Hague: Martinus Nijhoff.

Husserl, E. (1988). Cartesian meditations. Dordrecht: Kluwer. Husserl, E. (2001). Logical investigations. London: Routledge.

Jirásek, I. (2007). An experience and Heidegger's analysis of authentic existence. In H. Sheridan, L. A. Howe, \& K. Thompson (Eds.), Sporting reflections: Some philosophical perspectives (Sport, Culture \& Society, 8) (pp. 154-170). Oxford: Meyer \& Meyer Sport Ltd.

Kerry, D. S., \& Armour, K. M. (2000). Sport science and the promise of phenomenology: Philosophy, method, and insight. Quest, 52, 1-17.

Knaack, P. (1984). Phenomenological research. Western Journal of Nursing Research, 6, 107-114.

Kretchmar, R. S. (1974). Modes of philosophic inquiry and sport. Journal of the Philosophy of Sport, 1, 129-131.

Kretchmar, R. S. (2000). Movement subcultures: Sites for meaning. Journal of Physical Education, Recreation and Dance, 71(5), 19-25.

Loland, S. (2007). Outline of a phenomenology of snowboarding. In M. McNamee (Ed.), Philosophy, Risk and Adventure Sports (pp. 106-117). London: Routledge.

Martínková, I. (2006). Jan Patočka's three movements of human life with respect to physical education and sport practice. Acta Universitatis Palackianae Olomucensis. Gymnica, 36(2), 59-66.

Martínková, I. (2007). Time versus timelessness in relation to movement practice. In I. Martínková \& M. Peliš (Eds.), Movement: The art of life III (pp. 43-63). Praha: Charles University.

Martínková, I. (2012). Anthropos as kinanthropos: Hiedegger and Patočka on human movement. In I. Martínková \& J. Parry (Eds.), Phenomenological Approaches to Sport (pp. 33-44). London: Routledge.

Martínková, I., \& Parry, J. (2012). An introduction to the phenomenological study of sport. In I. Martínková \& J. Parry (Eds.), Phenomenological Approaches to Sport (pp. 1-17). London: Routledge.

McGinn, C. (2008). Sport: A philosopher's manual. Stockfield: Acumen.

McLaughlin, D. W., \& Torres, C. R. (2012). Sweet tension and its phenomenological description: Sport, intersubjectivity and horizon. In I. Martínková \& J. Parry (Eds.), Phenomenological Approaches to Sport (pp. 86-100). London: Routledge

Meier, K. V. (1975). Cartesian and phenomenological anthropology: The radical shift and its meaning for sport. Journal of the Philosophy of Sport, 2, 51-73.

Meier, K. V. (1984). A meditation on critical mass in the philosophy of sport. Journal of the Philosophy of Sport, 10, 8-20.

Merleau-Ponty, M. (1958). Phenomenology of perception. London: Routledge.

Merleau-Ponty, M. (1963). The structure of behavior. Boston: Beacon Press.

Merleau-Ponty, M. (1964). The philosopher and sociology. In Signs (pp. 98-113). Evanston, IL: Northwestern University Press.

Merleau-Ponty, M. (1968). The visible and the invisible. Evanston, IL: Northwestern University Press. 
Merleau-Ponty, M. (1996). Brouillon d'une rédaction [Unpublished manuscript for The visible and the invisible]. In Notes de cours au Collège de France 1958-1959 et 1960-1961 (pp. 355-378). Paris: Gallimard.

Moran, D. (2000). Introduction to phenomenology. New York, NY: Routledge.

Morris, K. J. (2003). Merleau-Ponty and "out-of-body experiences”. Journal of the British Society for Phenomenology, 34, 157-167.

Nesti, M. (2012). Phenomenology and sports psychology: Back to the things themselves! In I. Martínková \& J. Parry (Eds.), Phenomenological Approaches to Sport (pp. 101112). London: Routledge.

Nilges, L. M. (2004). Ice can look like glass: A phenomenological investigation of movement meaning in one fifthgrade class during a creative dance unit. Research Quarterly for Excercise and Sport, 75, 298-314.

Osterhoudt, R. G. (1974). Modes of philosophic inquiry concerning sport: some reflections on method. Journal of the Philosophy of Sport, 1, 137-141.

Papadimitriou, Ch. (2008). The "I" of the beholder: Phenomenological seeing in disability research. Sport, Ethics and Philosophy, 2, 216-233.

Patočka, J. (1998). Body, community, language, world. Chicago, IL: Open Court.

Polit, D. F., \& Hungler, B. P. (1999). Nursing research: Principles and methods. Philadelphia, PA: Lippincott Williams and Wilkins.

Polkinghorne, D. E. (1989). Phenomenological research methods. In R. S. Valle \& S. Halling (Eds.), Existentialphenomenological perspectives in psychology: Exploring the breadth of human experience (pp. 41-60). New York, NY: Plenum Press.
Rose, P., Beeby, J., \& Parker, D. (1995). Academic rigour in the lived experience of researchers using phenomenological methods in nursing. Journal of Advanced Nursing, 21, 1123-1129.

Ryall, E. (2008). Being-on-the-bench: An existential analysis of the substitute in sport. Sport, Ethics and Philosophy, 2, $56-70$.

Standal, O. F. \& Moe, V. F. (2012). Merleau-Ponty meets Kretchmar: Sweet tension of embodied learning. In I. Martínková \& J. Parry (Eds.), Phenomenological Approaches to Sport (pp. 72-85). London: Routledge.

Stewart, T. C. (2006). Understanding the experiences of a developmental student: A phenomenological study. Research \& Teaching in Developmental Education, 23, 64-77.

Stoll, S. K. (1982). The use of phenomenology to investigate and describe sport in the historical genre: An alternative approach to sport history. Quest, 34, 12-22.

Učník, L. (2007). Esse or habere. To be or to have: Patočka's critique of Husserl and Heidegger. Journal of the British Society for Phenomenology, 38, 297-317.

Vannatta, S. (2008). A phenomenology of sport: Playing and passive synthesis. Journal of the Philosophy of Sport, 35, 63-72.

Waldenfels, B. (2008). The central role of the body in Merleau-Ponty's phenomenology. Journal of the British Society for Phenomenology, 39(4), 76-87.

Walker, W. (2007). Ethical considerations in phenomenological research. Nurse Researcher, 14(3), 36-45.

Weiss, P. (1982). Some philosophical approaches to sport. Journal of the Philosophy of Sport, 9, 90-93. 